\title{
Phosphorous release from gross pollutant traps in urban environments
}

\author{
J.E. Ball \& J. Ara \\ School of Civil and Environmental Engineering, University of Technology Sydney, Australia
}

\begin{abstract}
Within Australia, gross pollutant traps (GPTs) have been installed in many stormwater drainage networks to improve the storm water quality before its discharge into receiving waters. These GPTs operate by filtering gross pollutants from the stormwater. In many GPTs these filtered pollutants are held within a wet sump until their removal. A significant fraction of the trapped litter can be classified as leaf litter. Before removal, this leaf litter may decay and hence has the potential to release nutrients into the stormwater. Therefore, nutrient management in stormwater needs to consider leaf litter decay trapped in GPTs. The decay of leaf litter stored in a GPT is discussed in the paper. Information for this discussion was obtained from a series of tests simulating the decay of leaf litter in a GPT. These tests used freshly fallen leaf litter collected from Centennial Park in Sydney, Australia.
\end{abstract}

\section{INTRODUCTION}

Stormwater runoff is a major threat to the quality of waterways and estuaries in urban areas. Urban runoff can carry litter, sediment, bacteria, nutrients, oils and heavy metals into waterways. This can result in urban waterways becoming unhealthy sources of drinking water, becoming unsuitable for swimming and other recreational activities, and being unable to support sensitive aquatic organisms. Management of stormwater quality, therefore, has become a topic of considerable interest and research activity (see, for example, Duncan 2006).

Within Australia, gross pollutant traps (GPTs) have been installed in many stormwater drainage networks to improve the storm water quality before its discharge into receiving waters. These GPTs operate by filtering gross pollutants from storm water through the use of coarse screens. In many GPTs the trapped pollutants are held within a wet sump until their removal. The trapped gross pollutants may be classified as litter, debris and sediments of which $80 \%$ is in organic in nature and primarily leaf litter (Ball, 2003). Before removal which occurs typically 2 to 4 times per year, this leaf litter may decay and hence has the potential to release both Phosphorous and Nitrogen into the water column; this Phosphorous and Nitrogen may then be flushed downstream by subsequent storm events.

An assessment of the importance of $\mathrm{P}$ release from leaf litter can be obtained from consideration of the nutrient content of leaf litter in urban stormwater. Allison et al. (1998) reported that the Phosphorous content in leaf litter was in the range of $0.05-0.45 \%$ of the dry leaf weight. Additionally, Allison et al. (1998) claimed that over time up to $20 \%$ of this Phosphorous could leach into the stormwater flow; the source of this claim, however, is not substantiated and needs to be validated. Prasad et al. (1980) in a series of experiments considered leaf litter from five alternative deciduous tree species commonly found in metropolitan Toronto, Canada and found that a 48 hour period was adequate to leach most of the soluble substances from the leaf litter. They do not comment, however, on the time-frame necessary for leaching of the decomposition by-products Phosphorous from the leaf litter. A longer time-frame was considered by $\mathrm{M}^{\mathrm{c}} \mathrm{Cann}$ and Michael (1995) in a series of experiments investigating the release rate of nutrients from Oak leaves. It was found that Phosphorous release was still occurring 28 days after the leaves were placed in water. This suggests that the Phosphorous release continues for an extended period of time after collection.

The period of Phosphorous release considered in these previous studies has been variable with the range being from 2 days to 28 days. The relevance of the period relates to the duration of the inter-event dry period. Previous studies have not considered this factor and hence 
research into the relationship between the release of Phosphorous from leaf litter and the duration of the inter-event dry period.

There are two aspects to the inter-event dry period; the first aspect is the inter-event dry period duration while the second aspect is the volume of the runoff event occurring at the end of the inter-event dry period. In respect of the first aspect, Heneker et al. (2001) reported on the analysis of rainfall records for estimation of parameters for a point rainfall generation model; this model was based the use of a rectangular pulse probability model for predicting the occurrence of storm rainfall. One of the parameters necessary for implementation of this rainfall model is the duration of the inter-event period between storm events which, for Sydney, was quoted as being $45.0 \mathrm{~h}$ with a standard deviation of $74.8 \mathrm{~h}$. For estimation of the rainfall depth at the end of the dry period, Heneker et al. (2001) noted that the stochastic nature of this aspect. Hence there is a need to consider alternative rainfall sequences to develop an understanding of how the rainfall depth during a storm event influences the downstream transport of the nutrients released from the decaying leaf litter.

Hence, while a few studies have considered the release of Phosphorous from leaf litter, these studies have not resulted in the development of appropriate models for prediction of the Phosphorous release from leaf litter collected in GPTs in Australian urban environments. Furthermore, these studies have highlighted the need for a systematic investigation of the processes influencing nutrient release from leaf litter stored in the wet sump of a GPT.

\section{PHOSPHOROUS IN STORMWATER}

Urban stormwater runoff has been identified as a major source of nutrients in urban waterways by, for example, Cordery (1977) and Herricks (1995). In Australian freshwater environments, Phosphorous is the major nutrient of concern. Phosphorous in urban waterways can be categorised into a number of divisions with the primary division being into organic and inorganic Phosphorous. Therefore, in discussing the decomposition of leaf litter, it is important to consider the different forms in which phosphorous can occur within an urban stormwater system. Shown in Tables 1 and 2 are the partitioning of Phosphorous in stormwater and sewage effluent as presented by Waller and Hart (1986) and by Ball and Abustan (1995).

Table 1. Phosphorous Partitions (after Waller and Hart, 1986).

\begin{tabular}{lccc}
\hline & Soluble P & \multicolumn{2}{c}{ Particulate P } \\
& & Organic & Inorganic \\
& $(\%)$ & $(\%)$ & $(\%)$ \\
\hline Sewage & 83 & 17 & 0 \\
Stormwater & 4.2 & 11.6 & 84.2 \\
\hline
\end{tabular}

Table 2. Proportion of Phosphorous Transported in a Particulate Form.

\begin{tabular}{ll}
\hline Particulate Percentage & Reference \\
\hline up to 90 & Camp Scott Furphy (1988) \\
99 & Hvitved-Jacobsen (1986) \\
$84-96$ & Ball and Abustan (1995) \\
\hline
\end{tabular}

As shown in Table 2 the majority of Phosphorous transported in urban stormwater runoff is particulate in nature. Decay of leaf litter trapped in a GPT, however, has the potential to result in a change in the relative importance of the soluble and particulate phases of Phosphorous. This change in the relative importance of the particulate and soluble phases of Phosphorous, in turn, will influence the effectiveness of downstream measures employed for treatment of stormwater borne Phosphorous; most treatment measures employed involve sedimentation of particulates or filtering of the stormwater.

3 CENTENNIAL PARK CATCHMENT

The Centennial Park Catchment (CPC) is located in the eastern suburbs of Sydney, approximately four kilometres southeast of Sydney's Central Business District (see Error! Reference source not found.). The total area of this highly urbanised catchment is 1.32 square 
kilometres with different forms of residential lots occupying more than half of the catchment. The catchment is drained by separate sewer and stormwater systems, with the storm water system consisting of a network of pipes, box culverts and open channels.

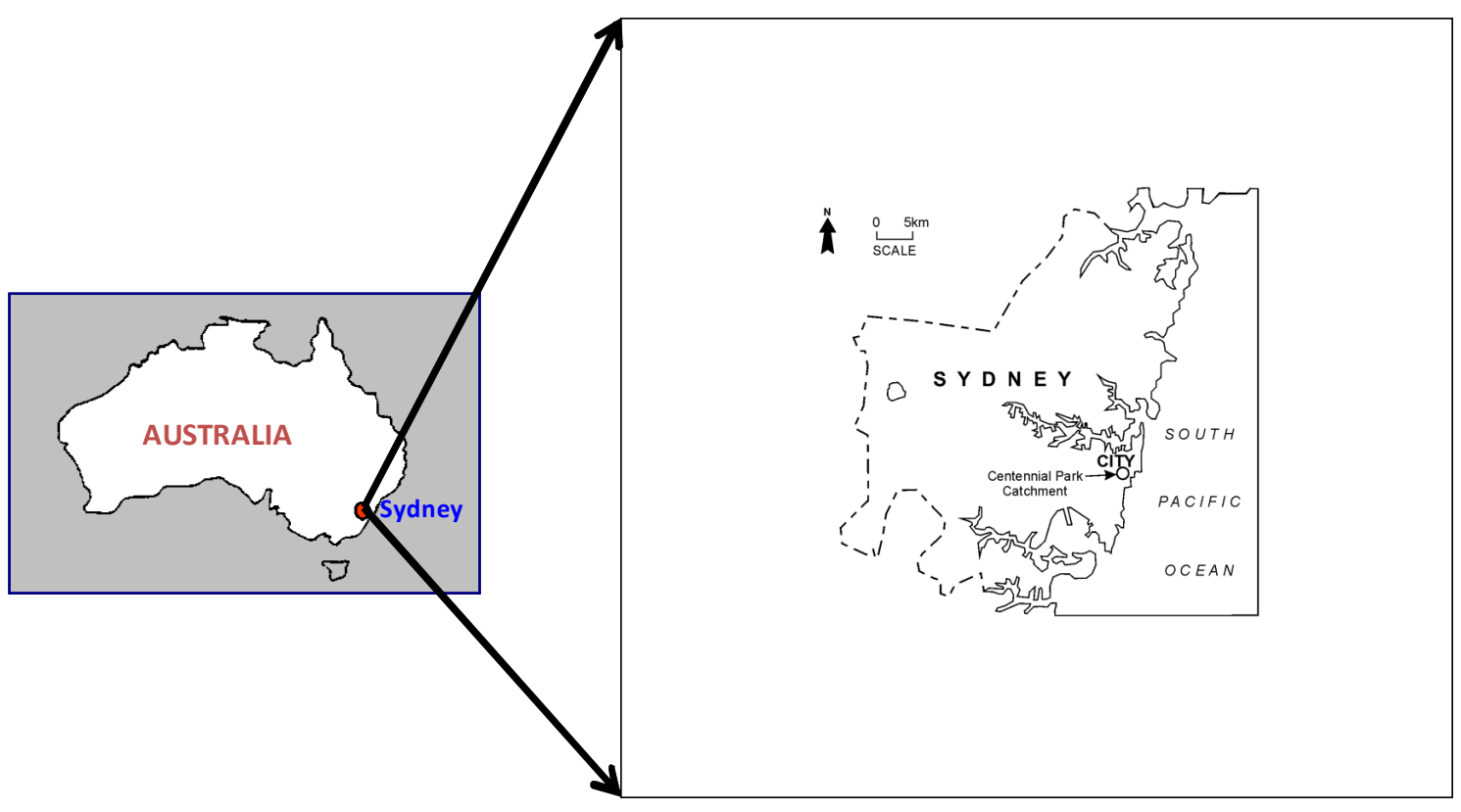

Figure 1. Location of Centennial Park Catchment

A gauging station monitoring both the quantity and quality of stormwater runoff from this catchment was installed at the outlet of the catchment immediately prior to constructed wetlands within Centennial Park. In the vicinity of this gauging station, a GPT was installed to minimise the mass of gross pollutants entering the wetlands.

Ball (2002) discusses details of this monitoring station. Additionally, Ball (2002) presents results from this gauging station which confirm the potential for changes in the relative importancee of the particulate and soluble phases of Phosphorous.

\section{EXPERIMENTAL APPROACH}

The first step in building a model for prediction of nutrient release from leaf litter stored in a GPT was to undertake simple laboratory scale experiments using leaf species typically found in the Centennial Park GPT. The major species tested were the Port Jackson Fig, Holm Oak and a broad leaf paper bark.

The experimental process was

1. Freshly fallen leaves were collected from the Centennial Park catchment area during dry weather;

2. The leaves were cleaned and air dried at approximately $21-23^{\circ} \mathrm{C}$ for up to 3 days;

3. Approximately $10 \mathrm{gm}$ of identical leaf species were placed in $5 \mathrm{~mm}$ mesh nylon litter bag in replicates of three with a total of 93 bags being prepared.

4. For the experiment, 3 (three) $20 \mathrm{~L}$ clean opaque buckets were filled with distilled water and bags of samples were placed in each bucket. Three bags were kept for initial total nutrient determination;

5. The buckets were allowed to remain undisturbed in the ambient laboratory environment. Samples were allowed to go anaerobic which is typical of the wet sump environment found in many GPTs.

6. Three parallel samples were collected from each bucket after 1, 5, 10, 15, 20, 30, 45, 60, 90 and 180 days. These samples were analysed for nutrients; and

7. A control was set up using the same buckets filled with the same distilled water but without the bags of leaves. 
For each sample, the $\mathrm{pH}$, electrical conductivity, and dissolved oxygen in the water were determined together with the total nitrogen and total phosphorus concentration in both the water and the leaves.

\section{TEST RESULTS}

Shown in Error! Reference source not found. and Table 3 are the cumulative mass of phosphorus released from the leaf litter during the experiment. The phosphorous remaining in the leaves is shown in. It was found that approximately $50 \%$ of the phosphorous in the leaf litter was released to the water during the first 22 days with the majority of the remainder being released over the next 150 days.

Table 3. Phosphorous Release from Leaf Litter with Time

\begin{tabular}{llll}
\hline $\begin{array}{l}\text { Decomposition } \\
\text { (days) }\end{array}$ & $\begin{array}{l}\text { Initial P in leaf } \\
\text { mg/g dry weight } \\
\text { (mean } \pm \text { SD) }\end{array}$ & $\begin{array}{l}\text { P leached from leaf litter } \\
\text { mg/g dry weight } \\
(\text { mean } \pm \text { SD) }\end{array}$ & \% leached \\
\hline 1 & $0.381 \pm 0.03$ & $0.043 \pm 0.002$ & 11.4 \\
5 & $0.381 \pm 0.03$ & $0.099 \pm 0.003$ & 26.2 \\
10 & $0.381 \pm 0.03$ & $0.141 \pm 0.007$ & 37.0 \\
15 & $0.381 \pm 0.03$ & $0.162 \pm 0.007$ & 42.6 \\
22 & $0.381 \pm 0.03$ & $0.207 \pm 0.053$ & 54.4 \\
37 & $0.381 \pm 0.03$ & $0.267 \pm 0.068$ & 70.1 \\
56 & $0.381 \pm 0.03$ & $0.305 \pm 0.068$ & 80.0 \\
70 & $0.381 \pm 0.03$ & $0.313 \pm 0.046$ & 82.1 \\
90 & $0.381 \pm 0.03$ & $0.333 \pm 0.024$ & 87.5 \\
180 & $0.381 \pm 0.03$ & $0.356 \pm 0.024$ & 93.4 \\
\hline
\end{tabular}

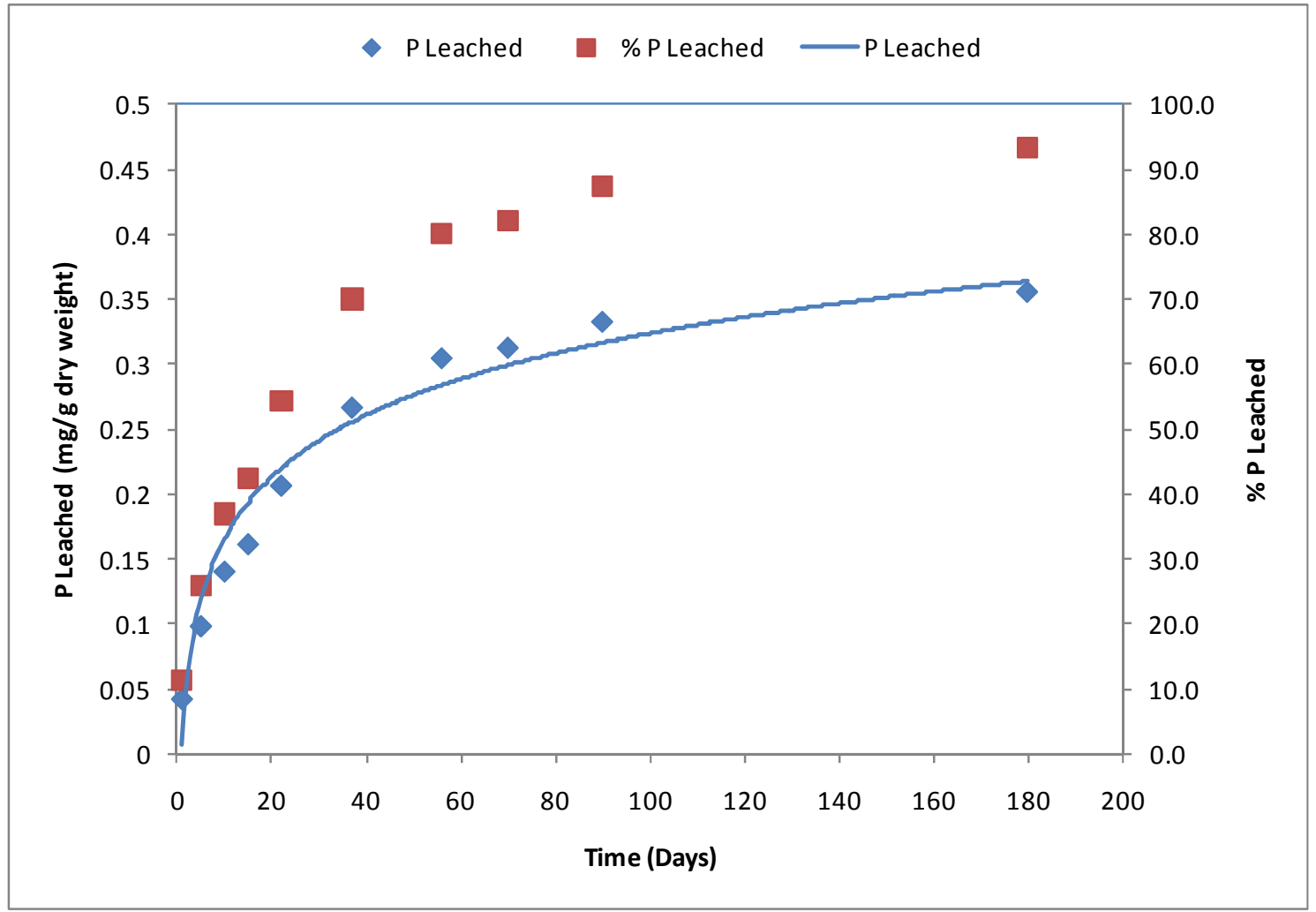

Figure 2. Phosphorous Released from Leaf Litter 


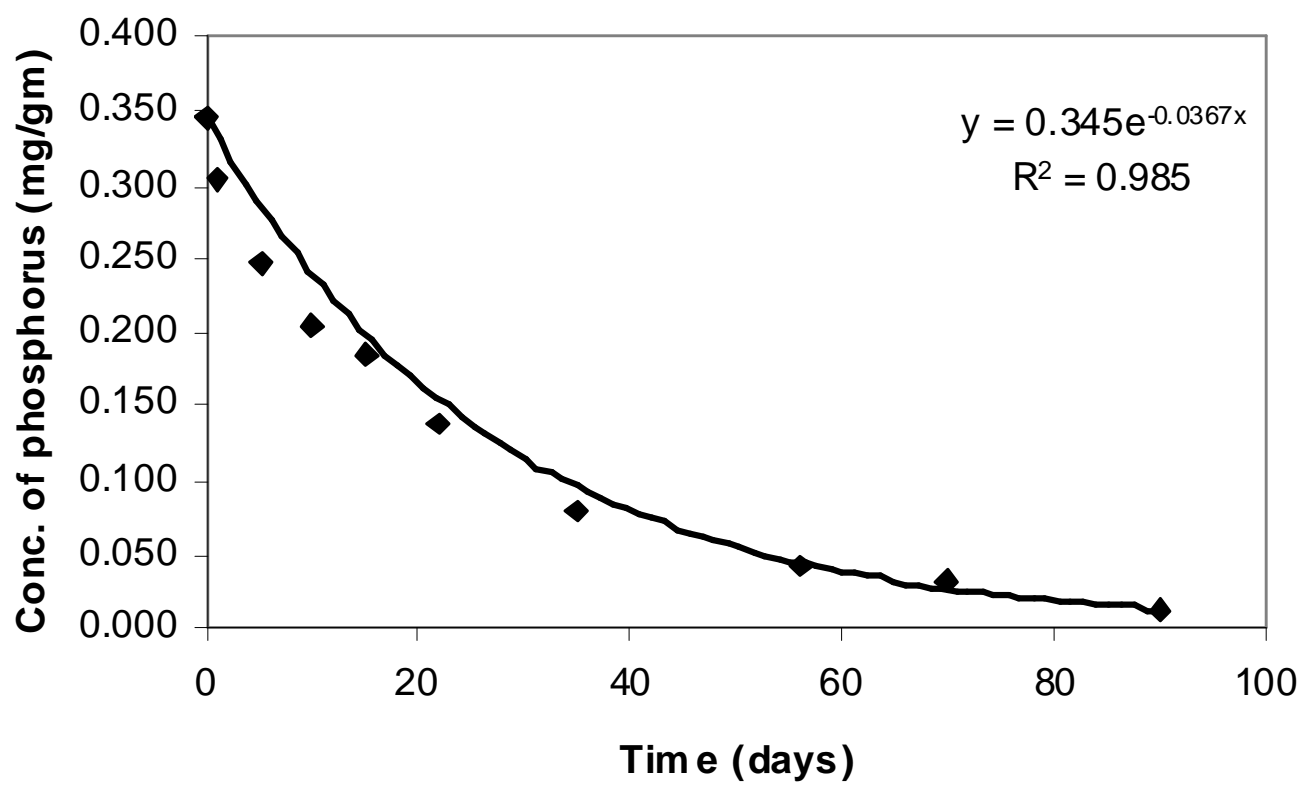

Figure 3. Phosphorous Remaining in Leaves

Many studies of the decomposition of plant material have assumed a first order exponential decay model which was proposed originally by Olson (1963). The basis of this model is

$$
P_{t}=P_{0} e^{-k t}
$$

where $\mathrm{P}_{0}$ is the initial phosphorus content in leaf litter, $\mathrm{P}_{\mathrm{t}}$ is the amount of phosphorus remaining after the time $t$, and $t$ is the time in days.

Analysis of the experimental data for the phosphorous remaining in the leaves with a first order decay model resulted in the decay constant being 0.0367 day- 1 . In other words, the phosphorous available in the leaf litter was approximately $3.7 \%$ less than that available the previous day. This decay in the phosphorous available for release from the leaf litter is illustrated in Figure 3.

As previously noted, the conductivity, the dissolved oxygen and $\mathrm{pH}$ were monitored during the experimental tests. It was found that the conductivity increased with time and that it was strongly correlated with concentration of total phosphorus in the water. On the other hand, the dissolved oxygen decreased with time and was negatively correlated with the phosphorous concentration. Finally, similar to the conductivity, the $\mathrm{pH}$ increased with time during the experiments; this is advantageous as a drop in $\mathrm{pH}$ leads to more acidic conditions and will impact on the release of particulate bound trace metals.

In summary, therefore, it was found that the conductivity and $\mathrm{pH}$ increased with time as the concentration of total phosphorus increased in the water, whereas dissolved oxygen decreased with time and an increase in the concentration of total phosphorus in the water. Additionally, conductivity and $\mathrm{pH}$ were positively correlated with the release of phosphorus from the leaf litter.

While the results presented have focussed primarily on the release of phosphorous from the leaf litter, preliminary results were obtained also for the release of nitrogen from the leaf litter. Shown in Table 4, is the Nitrogen remaining in the leaf litter during the first 30 days of the experiment. Analysis of these initial data suggests that the rate of Nitrogen release is less than the rate of Phosphorus release from the same leaves. These results for Nitrogen need confirmation once the full experimental data becomes available.

Table 4. Total Nitrogen remaining in Leaf Litter

\begin{tabular}{l|lllllll} 
Time (days) & 0 & 1 & 5 & 10 & 15 & 20 & 30 \\
TN (mg/gm) & 5.10 & 4.998 & 4.757 & 4.674 & 4.505 & 4.092 & 4.083 \\
\hline
\end{tabular}




\section{CONCLUSIONS}

The results of this study show that more than $50 \%$ of the Phosphorous in leaves was released within 22 days of submergence. In these experiments, it was found that the content of Phosphorous and Nitrogen in leaf litter was $0.087 \%$ and $1.28 \%$ respectively and the release of Phosphorous in $24 \mathrm{hr}$ was $0.11 \mathrm{mg} / \mathrm{g}$ of dry weight which is consistent with previous values published in the literature. Consideration of these results suggests that the leaching process of nutrients, especially phosphorus, from leaf litter provides considerable contribution to the eutrophication of the receiving water. Based on these preliminary results, in order to avoid significant leaching of leaf litter nutrients it is desirable to remove leaf litter from GPTs that submerge the collected leaf litter within 5 days of collection. If these devices are not cleaned regularly a large percentage of the nutrient from leaf litter collected in the GPT will be released and will be flushed downstream.

\section{REFERENCES}

Allison, RA, Chiew, FHS, and $\mathrm{M}^{\mathrm{c}}$ Mahon, TA, (1998), Nutrient contribution of leaf litter in urban stormwater, Journal of Environmental Management, 54:269-272.

Ball, JE, (2002), Stormwater quality at Centennial Park, Sydney, Australia, Research Report 205, Water Research Laboratory, School of Civil and Environmental Engineering, The University of New South Wales, ISBN: 0/85824/045/9

Ball, JE and Abustan, I, (1995), An investigation of the particle size distribution during storm events on an urban catchment, Proc. Second International Symposium on Urban Stormwater Management, 1995, I.E.Aust., Melbourne, Australia, I.E.Aust. Nat. Conf. Pub. 95/3, pp 531-535.

Camp Scott Furphy, (1988), Urban Runoff Study - Report of the Joint Councils River Committee, Unpublished Report for Hawkesbury Shire Council, Windsor, NSW, Australia.

Cordery, I, (1977), Quality characteristics of urban stormwater in Sydney, Australia, Water Resources Research, 13:197-202.

Duncan, H, (2006), Urban Stormwater Pollutant Concentrations and Loads, Chapter 4 in Australian Runoff Quality, T Wong Editor, National Committee for Water Engineering, Engineers Australia, Canberra, ISBN 0858258609, 231pp.

Heneker, TM, Lambert, MF, and Kuczera, G, (2001), A point rainfall model for risk-based design, Journal of Hydrology, 247:54-71.

Herricks, EE, (1995), Stormwater Runoff and Receiving Systems: Impact, Monitoring, and Assessment, CRC Lewis Publishers, Boca Raton, USA.

Hvitved-Jacobsen, T, (1986), Conventional Pollutant Impacts on Receiving Water, in Urban Runoff Pollution, HC Torno, J Marsalek, and M Desbordes, Springer-Verlag, New York, NY, USA.

$\mathrm{M}^{\mathrm{c} C a n n}$, K and Michael, J, (1995), Nutrient Content and Release Rate in Water of Oak Leaves, Unpublished Report, Stormwater Utility Bureau, City of Orlando, Orlando, USA.

Olson, JS, (1963), Energy storage and the balance of decomposers in ecological systems, Ecology, 44:322-332.

Prasad, D, Henry, JG, and Kovacko, R, (1980), Pollution potential of autumn leaves in urban runoff, Proc. International Symposium on Urban Storm Runoff, Kentucky, USA, pp 197-202.

Waller, D and Hart, WC, (1986), Solids, nutrients and chlorides in urban runoff, in Urban Runoff Pollution, HC Torno, J Marsalek, and M Desbordes, Springer-Verlag, New York, NY, USA. 